\title{
Theoretical Evaluation for the Function of Economical and Green Conducting Composite Material-based Chip for Jamaican Vomiting Sickness Diagnostics
}

Volodymyr V. Tkach 1,2,*iD, Marta V. Kushnir ${ }^{1}$, Sílvio C. de Oliveira ${ }^{2}$, Alina Yo. Zavolovych ${ }^{3, *}$, Viktoria O. Tkach ${ }^{4}$, Hanna Ya. Mytrofanova ${ }^{4}$, Anatolii O. Zadoia ${ }^{4}$, Petro I. Yagodynets' ${ }^{\prime}$,* , Zholt O. Kormosh ${ }^{5}$, Olga V. Luganska' ${ }^{6}$, Vira V. Kopiika ${ }^{6}$, Galyna M. Pochenchuk' ${ }^{1}$, Dilfuza M. Musayeva ${ }^{7}$, Hanifa Zh. Salomova $^{7}$

1 Chernivtsi National University, 58000, Kotsyubyns'ky Str. 2, Chernivtsi, Ukraine

2 Universidade Federal de Mato Grosso do Sul, Av. Sen. Felinto. Müller, 1555, C/P. 549, 79074-460, Campo Grande, MS, Brazil

3 Bukovinian State Medical University, 58001, Teatralna Sq., 9, Chernivtsi, Ukraine

4 Alfred Nobel University, 49000, Naberezhnaya Sicheslavska Str., 18, Dnipro, Ukraine

5 EasternEuropean National University, 43000, Voli Ave., 13, Lutsk, Ukraine

6 Zaporizhzhia National University, 69600, Zhukovsky Str. 68, Zaporizhzhia, Ukraine

7 Abu Ali Ibn Sino Bukhara State Medical Institute, 705018, Navoi Str., 1, Bukhara, Uzbekistan

* Correspondence: nightwatcher2401@gmail.com (V.V.T.); alina0515@gmail.com (A.Y.Z.); ved1988mid@rambler.ru (P.I.Y.);

Received: 15.09.2020; Revised: 14.10.2020; Accepted: 16.10.2020; Published: 18.10.2020

\begin{abstract}
A possibility of an economical and green conducting-polymer composite base chip for Jamaican vomiting sickness diagnostics by hypoglycin electrochemical determination has been evaluated. The correspondent mathematical model has been developed and analyzed by means of linear stability theory and bifurcation analysis. It has been detected that the chip is efficient for either reduced or semi-oxidized form determination in an efficient manner, so it may serve as a rapid hypoglycin intoxication diagnostics tool. On the other hand, as all of the correspondent components possess amino acid moieties, influencing the double electric layer ionic forces.
\end{abstract}

Keywords: Jamaican vomiting sickness; hypoglycin; electrochemical chip; conducting polymer; copper sulfide nanoparticles; stable steady-state.

(C) 2020 by the authors. This article is an open-access article distributed under the terms and conditions of the Creative Commons Attribution (CC BY) license (https://creativecommons.org/licenses/by/4.0/).

\section{Introduction}

Jamaican vomiting sickness is considered one of the neglected tropical diseases (NTD), characterized by multiple organism poisoning [1 - 4]. It is caused by consuming of immature (unripe) tropical fruits (principally, ackee or litchi, growing mostly in Jamaica) and leads to the multiple organism intoxication, the high-amplitude oscillation of carbohydrate concentration, failures in fatty acid metabolism. In grave cases, coma and even death may occur. These effects are caused by an aminoacid hypoglycin (Fig. 1):<smiles>C=C1CC1CC(N)C(=O)O</smiles>

Figure 1. Hypoglycin. 
Technically, hypoglycin is an alanine derivative but much more active. It is considered protoxin. In other words, it isn't toxic by itself, but its metabolism path leads to highly toxic products, as described below.

Possessing both cycloalkane and alkene fragment, hypoglycinis easily oxidized, yielding a glycerine-like triol fragment [5 - 10], which interferes with the fatty acid metabolism, esterifying them. Also, this triol is oxidized, yielding a diketoaldehyde and diketoacids, possessing an active methylene group, which is also oxidized, yielding the tetroselike fragment, responsible for the carbohydrate-sensitive response. As the amino acid fragment remains in all the mentioned forms, the protein biosynthesis remains affected by all the metabolic forms, resulting in multiple intoxications, coma, and even death. As the consequences of the action of hypoglycin are grave and dose-related, the development of a rapid and efficient way for its determination remains actual [3-10].

As for now, no electrochemical method for hypoglycin determination has been developed. Nevertheless, its chemical composition and behavior in the organism indicate that it is electrochemically active. As both alkene and cycloalkane fragment are easily oxidized in basic media, copper (II) sulfide, paired with copper (III) sulfohydroxide [11 - 17], active in this media, is preferred as an electrode modifier. It is a p-type semiconductor capable of substituting titanium dioxide in sensors and other semiconducting apparels, but with more flexible electrochemical behavior.

It is convenient to insert $\mathrm{CuS}$ into an organic oligo- (including a squaraine dye [18 23]) or polymeric [24-28] matrix. It implements both mediating and stabilizing function in the electroanalytical system. The composite has the aim to reduce the oxidation overvoltage and to catalyze the analyte oxidation.

Nevertheless, the use of novel electrode modifiers with novel analytes may be impeded by: - the indecision concerning the exact mechanism of electrochemical reaction;

- the necessity of determination of the parameter region, correspondent to the most efficient active substance and mediating action;

- the presence of electrochemical instabilities accompanying the electrochemical oxidation of organic molecules (including electrochemical polymerization of heterocyclic compounds) [29-32].

The mentioned problems may only be solved by means of an analysis of a mathematical model capable of describing the hypoglycin hypoglycin-assisted electrochemical determination adequately. Moreover, it is also capable compare the behavior of this system with that of similar ones without any experimental essay.

So, the goal of this work is the mechanistic theoretic analysis of the hypoglycin electrochemical determination, assisted by $\mathrm{CuS}$ - Conducting Polymer composite, providing an economical and ecologically secure rapid diagnostic tool. In order to achieve it, we realize the specific goals:

- a suggestion of the mechanism of the reaction consequence, leading to the appearance of an analytical signal;

- development of the balance equation mathematical model, correspondent to the electroanalytical system;

- analysis and interpretation of the model in terms of the electroanalytical use of the system;

- the seek for the possibility of electrochemical instabilities and for the factor causing them; the comparison of the mentioned system's behavior with similar ones [33 - 35]. 


\section{Materials and Methods}

\subsection{System and its modeling.}

As a matter of fact, the mechanism of the hypoglycin $\mathrm{CuS}$ - assisted electrochemical oxidation is mimicking its natural metabolism in the human body. In the first stage, the Wagner reaction is realized (Fig. 2):

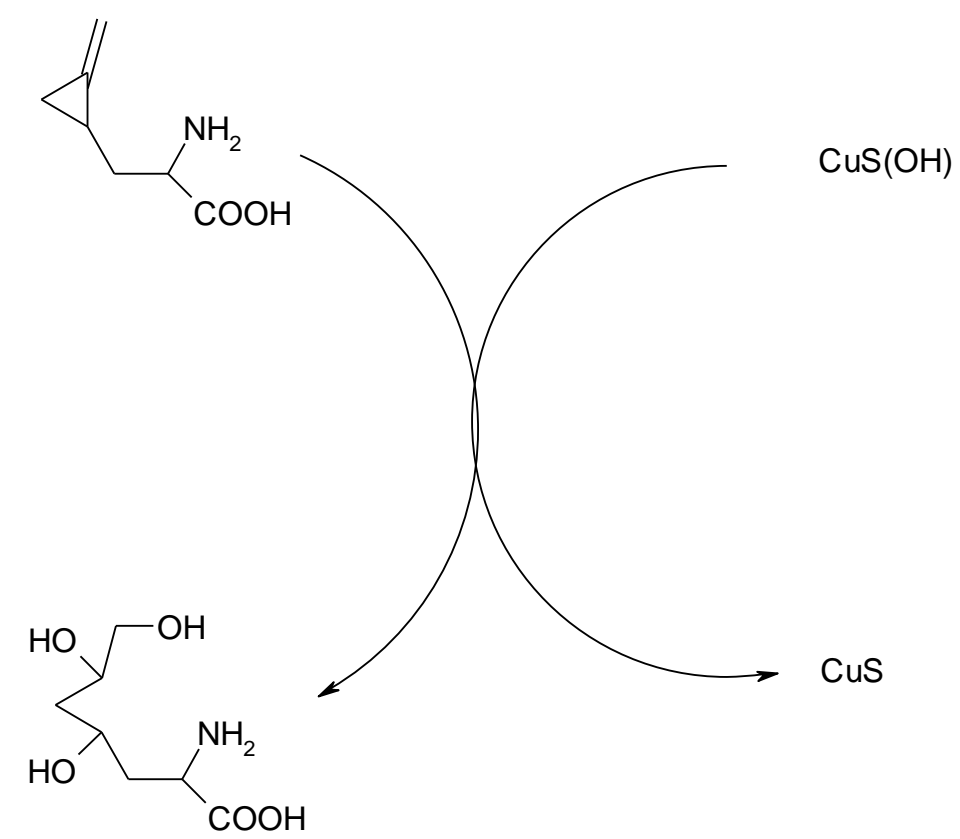

Figure 2. The reaction on the first chemical stage (slow).

As triol derivative is more readily oxidized by $\mathrm{CuS}(\mathrm{OH})$, the second stage, yielding the tricarbonyl derivative, will be faster (Fig. 3):

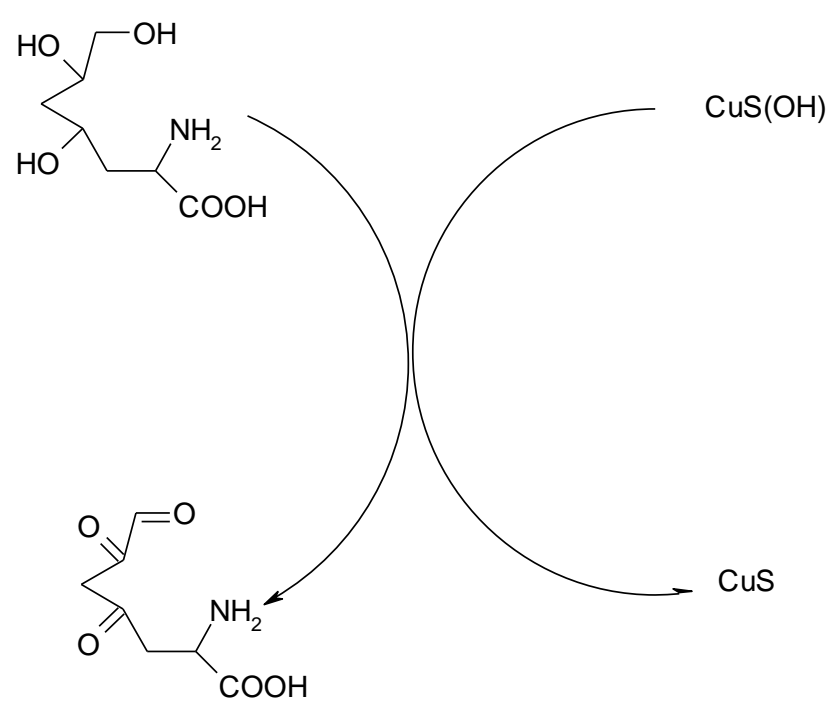

Figure 3. The reaction on the second chemical stage (fast).

The electrochemical stage converts a less active $\mathrm{CuS}$ to a more active trivalent copper form, according to the equation:

$$
\mathrm{CuS}+\mathrm{OH}^{-}-\mathrm{e}^{-} \rightarrow \mathrm{CuS}(\mathrm{OH})
$$


As for now, the behavior of the system with hypoglycin electrochemical determination, assisted by $\mathrm{CuS}$ - Conducting Polymer composite, will be depicted by a classical trivariate model, very similar to that described in [33 - 35] in our recent works, but a bit more dynamic. The variables introduced to the system are:

$\mathrm{h}$ - hypoglycin concentration in the pre-surface layer;

$\mathrm{h}^{*}$ - hypoglycin triol derivative concentration in the pre-surface layer;

c- copper (II) sulfide surface coverage degree.

To simplify the modeling, we suppose that the reactor is intensively stirred, so we can neglect the convection flow. Also, we assume that the background electrolyte is in excess, so we can neglect the migration flow. The diffusion layer is supposed to be of a constant thickness, equal to $\delta$, and the concentration profile in it is supposed to be linear.

It is possible to show that the electroanalytical process will be described by the threedimensional equation set, exposed as:

$$
\left\{\begin{array}{c}
\frac{d h}{d t}=\frac{2}{\delta}\left(\frac{\Delta}{\delta}\left(h_{0}-h\right)-r_{W}\right) \\
\frac{d h *}{d t}=\frac{2}{\delta}\left(r_{W}-r_{O}\right) \\
\frac{d c}{d t}=\frac{1}{C}\left(r_{W}+r_{O}-r_{1}\right)
\end{array}\right.
$$

Herein, $\Delta$ is the diffusion coefficient, $\mathrm{h}_{0}$ is the hypoglycin bulk concentration, $\mathrm{C}$ is the maximal $\mathrm{CuS}$ surface concentration, $\mathrm{rw}_{\mathrm{w}}$ is the Wagner reaction rate, ro is the triol oxidation rate, and $r_{1}$ is the electrochemical stage rate.

The correspondent reaction rates may be calculated as $(2-4)$ :

$$
\begin{aligned}
& r_{W}=k_{W} h(1-c)^{3} \exp (-a h) \\
& r_{O}=k_{O} h *(1-c)^{6} \exp (-a h *) \\
& r_{1}=k_{1} c \exp \left(\frac{F \varphi_{0}}{R T}\right)
\end{aligned}
$$

in which the parameters $\mathrm{k}$ are the correspondent rate constants, $\mathrm{a}$ is the parameter relating the chemical stages' kinetics to double electric layer (DEL) ionic force, $\mathrm{F}$ is the Faraday number, $\varphi_{0}$ is the potential slope in DEL, related to the zero charge potential, $\mathrm{R}$ is the universal gas constant and $\mathrm{T}$ is the absolute temperature. Herein, the elementary electrochemical act involves a one-electron transfer, regenerating the highly energetic (and, correspondently, more active) trivalent copper.

Although in alkaline media in this system the DEL influences of the chemical stages are minimized, in strongly alkaline media, the enhancement in the number of active hydroxyl groups will give much more impact to the DEL ionic force than for the simple case [33 - 35]. This impact will play an important part in the electrochemical behavior of the system, as exposed below.

\section{Results and Discussion}

In order to describe the behavior of the system with hypoglycin electrochemical determination, assisted by a composite $\mathrm{CuS}$ - Conducting polymer, we analyze the equation set (1) by means of linear stability theory and bifurcation analysis. The steady-state Jacobian matrix members will be exposed as:

in which:

$$
\left(\begin{array}{lll}
a_{11} & a_{12} & a_{13} \\
a_{21} & a_{22} & a_{23} \\
a_{31} & a_{32} & a_{33}
\end{array}\right)
$$




$$
\begin{aligned}
& a_{11}=\frac{2}{\delta}\left(-\frac{\Delta}{\delta}-k_{W}(1-c)^{3} \exp (-a h)+a k_{W} h(1-c)^{3} \exp (-a h)\right) \\
& a_{12}=0 \\
& a_{13}=\frac{2}{\delta}\left(3 k_{W}(1-c)^{2} \exp (-a h)\right) \\
& a_{21}=\frac{2}{\delta}\left(k_{W}(1-c)^{3} \exp (-a h)-a k_{W} h(1-c)^{3} \exp (-a h)\right) \\
& a_{22}=\frac{2}{\delta}\left(-k_{O} *(1-c)^{6} \exp (-a h *)+a k_{O} h *(1-c)^{6} \exp (-a h *)\right) \\
& a_{23}=\frac{2}{\delta}\left(6 k_{O} h *(1-c)^{5} \exp (-a h)-3 k_{W}(1-c)^{2} \exp (-a h *)\right) \\
& a_{31}=\frac{1}{c}\left(k_{W}(1-c)^{3} \exp (-a h)\right) \\
& a_{32}=\frac{1}{c}\left(k_{O} *(1-c)^{6} \exp (-a h *)\right) \\
& a_{33}=\frac{1}{C}\left(-6 k_{O} h *(1-c)^{5} \exp (-a h *)-3 k_{W}(1-c)^{2} \exp (-a h)-k_{1} \exp \left(\frac{F \varphi_{0}}{R T}\right)+\right. \\
& \left.j k_{1} c \exp \left(\frac{F \varphi_{0}}{R T}\right)\right)
\end{aligned}
$$

Taking into account that the amino acids are transformed, affecting neither amino nor carboxylic groups, multiple ionic forms appear in DEL, cyclically augmenting and diminishing its ionic forces. Therefore, the oscillatory behavior will be far more probable than in similar systems $[33-35]$.

Besides of the element $j k_{1} c \exp \left(\frac{F \varphi_{0}}{R T}\right)>0$, if $\mathrm{j}>0$, defining the DEL and matrix conductivity influences of the electrochemical stage, causing the oscillatory behavior, characteristic to all similar systems [33 - 35], the positivity of the elements $a k_{W} h(1-$ $c)^{3} \exp (-a h)$ and $a k_{O} h *(1-c)^{6} \exp (-a h *)$, if a>0, defines the oscillatory behavior realization by a more dynamic and interesting mechanism.

In the first stage, the Wagner reaction realization puts to the molecule three hydroxyl groups, which, in a strongly alkaline medium, are easily ionized, yielding a more ionic form than the initial hypoglycin ion. Thus, the DEL ionic force and conductivity augment. Afterward, as the alkoxyl ions are oxidized to a less ionic carbonyl forms, still attached to the alanine fragment, the DEL ionic force and conductivity diminish, providing the cyclic changes in the layer structure, capacitance, and conductivity.

These changes do not manifest themselves significantly within the detection limit but may be easily represented far beyond it.

Yet if the mentioned elements remain negative, the steady-state stability is warranted. Really, applying the Routh-Hurwitz criterion to the Jacobian matrix and introducing new variables, having it rewritten as (16):

$$
\frac{4}{\delta^{2} V}\left|\begin{array}{ccc}
-\kappa_{1}-\Xi & 0 & \Sigma \\
\Xi & -\Omega & \Phi \\
\Xi & \Omega & -\Sigma-\Phi-\Lambda
\end{array}\right|
$$

and opening the brackets and applying the condition Det $\mathrm{J}<0$, salient from the criterion, we obtain the steady-state stability requirement (14):

$$
-\kappa_{1}(\Omega \Sigma+\Omega \Lambda)-\Xi(\Omega \Lambda-\Omega \Sigma)<0
$$

which is readily satisfied in the case of the negativity of $\mathrm{j}$ and a. It defines a relatively vast parameter region of the steady-state stability. From the electroanalytical point of view, it is correspondent to the linear dependence between the electrochemical parameter and the aminoacid concentrations, describing an efficient electroanalytical process, even more, stable than in similar systems [33 - 35]. Therefore, the $\mathrm{CuS}$ - Conducting Polymer composite may be readily used in the chips for diagnostics of Jamaican vomiting sickness. 
As the first chemical stage is slow, the system tends to be either diffusion or kinetically controlled. The principal factor in systems with a large electrode and small concentration is diffusion. Yet in the systems with a small electrode and concentrated solutions, the principal factor is the kinetics of the first stage.

The detection limit is defined by the monotonic instability, depicting the margin between the stable steady-states and unstable states. Its condition is Det $\mathbf{J}=0$, and, for this system:

$$
-\kappa_{1}(\Omega \Sigma+\Omega \Lambda)-\Xi(\Omega \Lambda-\Omega \Sigma)=0
$$

As a matter of fact, this chip is capable of detecting the Jamaican vomiting sickness in particular and hypoglycin poisoning in general in an efficient manner. It may be used either in vivo or in vitro, being capable of detecting hypoglycin in fruit samples, juices, nectars saliva, blood, tears, and fat tissue (where either hypoglycin or its glycol derivative may be detected). The peak separation with the main interferent compounds (ethanol, glycerol, glycine, and other amino acids) is achieved by the difference in the kinetics of the interaction of the electrode modifier with the analyte and the interfering compounds.

\section{Conclusions}

From the system with the electrochemical determination of hypoglycin on a $\mathrm{CuS}$ composite with conducting polymer, it was possible to conclude that the mentioned composite may be readily used in the chips for diagnostics of Jamaican vomiting sickness. This system will be readily stable and electroanalytical efficient, being either diffusion or kinetically controlled. Yet the oscillatory behavior in this system is possible, as the amino acid ionic forms' transformation is influencing the DEL ionic force, will be more probable than in similar systems.

\section{Funding}

This research received no external funding.

\section{Acknowledgments}

This research has no acknowledgment.

\section{Conflicts of Interest}

The authors declare no conflict of interest.

\section{References}

1. Yang, J.; Zhu, X.; Zhang, P.; Wang, Y.; Xiao, Y.; Yang, B.; Qu, H.; Jiang, Y. Detection of toxic methylenecyclopropylglycine and hypoglycin A in litchi aril of three Chinese cultivars. Food Chemistry 2020, 327, https://doi.org/10.1016/j.foodchem.2020.127013.

2. Dutta, D.; Khandelwal, D.; Kalra, S. Litchi-related Hypoglycemia: A Public Health Challenge, an Endocrine Opportunity. Indian J Endocrinol Metab 2019, 23, 380-381, https://doi.org/10.4103/ijem.IJEM_235_19.

3. Asthana, S.; Dixit, S.; Srivastava, A.; Kumar, A.; Singh, S.P.; Tripathi, A.; Das, M. Methylenecyclopropyl glycine, not pesticide exposure as the primary etiological factor underlying hypoglycemic encephalopathy in Muzaffarpur, India. Toxicology Letters 2019, 301, 34-41, https://doi.org/10.1016/j.toxlet.2018.10.033.

4. Tripathi, J.; Bandyopadhyay, N.; Hajare, S.; Wadhawan, S.; Sarma, H.D.; Gautam, S. Determination of Tolerable Dose of Litchi Fruit Considering Reported Hypoglycin A And MCPG Contents through Biochemical and Histopathological Evaluations in Mice. Current Science 2019, 117. 
5. Grande-Tovar, C.D.; Delgado-Ospina, J. Puerta, L.; Rodríguez, G.C.; Sacchetti, G.; Paparella, A.; ChavesLópez, C. Bioactive micro-constituents of ackee arilli (Blighia sapida K.D. Koenig). An. Acad. Bras. Cien. 2019, 91, https://doi.org/10.1590/0001-3765201920180140.

6. Ajayi, A.M.; Ayodele, E.O.; Ben-Azu, B.; Aderibigbe, A.O.; Umukoro, S. Evaluation of neurotoxicity and hepatotoxicity effects of acute and sub-acute oral administration of unripe ackee (Blighia sapida) fruit extract. Toxicology Reports 2019, 6, 656-665, https://doi.org/10.1016/j.toxrep.2019.06.019.

7. Surmaitis, R.; Hamilton, R.J. Ackee fruit toxicity. StatPearls 2020.

8. Cooper, A.M.; Felix, D.; Alcantara, F.; Zaslavsky, I.; Work, A.; Watson, P.L.; Pezzoli, K.; Yu, Q.; Zhu, D.; Scavo, A.J.; Zarabi, Y.; Schroeder, J.I. Monitoring and mitigation of toxic heavy metals and arsenic accumulation in food crops: A case study of an urban community garden. Plant Direct 2020, 4, https://doi.org/10.1002/pld3.198.

9. Pateriya, A.; Verma, R.K.; Sankhla, M.S.; Kumar, R. Heavy Metal Toxicity in Rice and its Effects on Human Health. Lett. Appl. NanoBioSci. 2021, 10, 1833-1845, https://doi.org/10.33263/LIANBS101.18331845.

10. Patel, G.; Dalwadi, C. Cytotoxicity and Cellular Uptake of 5-Fluorouracil Loaded Methylcellulose Nanohydrogel for Treatment of Oral Cancer. Lett. Appl. NanoBioSci. 2021, 10, 1904-1918, https://doi.org/10.33263/LIANBS101.19041918.

11. Li, C.; Wang, Y.; Jiang, H.; Wang, X. Biosensors Based on Advanced Sulfur-Containing Nanomaterials. Sensors 2020, 20, https://doi.org/10.3390/s20123488.

12. Hoffmann, K.; Bouchet, S.; Christl, I.; Kaegi, R.; Kretzschmar, R. Effect of NOM on copper sulfide nanoparticle growth, stability, and oxidative dissolution. Environmental Science: Nano 2020, 7, 1163-1178, https://doi.org/10.1039/C9EN01448A.

13. Huynh, T.-P. Chemical and biological sensing with nanocomposites prepared from nanostructured copper sulfides. Nano Futures 2020, 4.

14. Colipai, C.; Southam, G.; Oyarzún, P.; González, D.; Díaz, V.; Contreras, B.; Nancucheo, I. Synthesis of Copper Sulfide Nanoparticles Using Biogenic H2S Produced by a Low-pH Sulfidogenic Bioreactor. Minerals 2018, 8, https://doi.org/10.3390/min8020035.

15. Shakir, I.; Almutairi, Z. Rational Solution-assisted Synthesis of Copper Sulfide Nanoparticles for Ultrahighrate Electrochemical Energy Storage. AAAFM Energy 2020, 1, 1-8, https://doi.org/10.24911/AAAFM/Energy/23-1559239669.

16. Laís, S.P.; Daniela, N.S.; Ana Elisa, F.D.O.; Arnaldo, C.P.; Keyller, B.B. Carbon nanomaterials: synthesis and applications to development of electrochemical sensors in determination of drugs and compounds of clinical interest. Reviews in Analytical Chemistry 2019, 38, https://doi.org/10.1515/revac-2019-0017.

17. Rajaram, R.; Kiruba, M.; Suresh, C.; Mathiyarasu, J.; Kumaran, S.; Kumaresan, R. Amperometric determination of Myo-inositol using a glassy carbon electrode modified with nanostructured copper sulfide. Microchimica Acta 2020, 187, https://doi.org/10.1007/s00604-020-04300-z.

18. Lima, E.; Boto, R.E.; Ferreira, D.; Fernandes, J.R.; Almeida, P.; Ferreira, L.F.V.; Souto, E.B.; Silva, A.M.; Reis, L.V. Quinoline- and Benzoselenazole-Derived Unsymmetrical Squaraine Cyanine Dyes: Design, Synthesis, Photophysicochemical Features and Light-Triggerable Antiproliferative Effects against Breast Cancer Cell Lines. Materials 2020, 13, 2646-2660, https://doi.org/10.3390/ma13112646.

19. Gomes, V.S.D.; Gonçalves, H.M.R.; Boto, R.E.F.; Almeida, P.; Reis, L.V. Barbiturate squaraine dyes as fluorescent probes for serum albumins detection. Journal of Photochemistry and Photobiology A: Chemistry 2020, 400, https://doi.org/10.1016/j.photochem.2020.112710.

20. Butnarasu, C.; Barbero, N.; Barolo, C.; Visentin, S. Squaraine dyes as fluorescent turn-on sensors for the detection of porcine gastric mucin: A spectroscopic and kinetic study. Journal of Photochemistry and Photobiology B: Biology 2020, 205, https://doi.org/10.1016/j.jphotobiol.2020.111838.

21. Maeda, T.; Liess, A.; Kudzus, A.; Krause, A.-M.; Stolte, M.; Amitani, H.; Yagi, S.; Fujiwara, H.; Würthner, F. Hydrogen bond-rigidified planar squaraine dye and its electronic and organic semiconductor properties. Chemical Communications 2020, 56, 9890-9893, https://doi.org/10.1039/D0CC04306K.

22. Chen, Y.; Wang, S.; Li, Z. A cobalt-pyrrole coordination compound as high performance cathode catalyst for direct borohydride fuel cells. RSC Advances 2020, 10, 29119-29127, https://doi.org/10.1039/D0RA05143H.

23. Aguilera, L.; Aguiar, P.C.M.; Ruiz, Y.L.; Almeida, A.; Moreira, J.A.; Passos, R.R.; Pocrifka, L.A. Electrochemical synthesis of $\gamma-\mathrm{CoOOH}$ films from $\alpha-\mathrm{Co}(\mathrm{OH}) 2$ with a high electrochemical performance for energy storage device applications. Journal of Materials Science: Materials in Electronics 2020, 31, 30843091, https://doi.org/10.1007/s10854-019-02853-1.

24. Shamraiz, U.; Badshah, A.; Raza, B. Ultrafine $\alpha-\mathrm{CoOOH}$ Nanorods Activated with Iron for Exceptional Oxygen Evolution Reaction. Langmuir 2020, 36, 2223-2230, https://doi.org/10.1021/acs.langmuir.9b03293.

25. Bagheri, A.; Hassani Marand, M. Voltammetric and Potentiometric Determination of $\mathrm{Cu} 2+\mathrm{Using}$ an Overoxidized Polypyrrole Based Electrochemical Sensor. Russian Journal of Electrochemistry 2020, 56, 453-461, https://doi.org/10.1134/S1023193520060026.

26. Jiang, W.-X.; Liu, W.-X.; Wang, C.-L.; Zhan, S.-Z.; Wu, S.-P. A bis(thiosemicarbazonato)-copper complex, a new catalyst for electro- and photo-reduction of CO2 to methanol. New Journal of Chemistry 2020, 44, 2721-2726, https://doi.org/10.1039/C9NJ05672F. 
27. Xiang, H.; Cai, Q.; Li, Y.; Zhang, Z.; Cao, L.; Li, K.; Yang, H. Sensors Applied for the Detection of Pesticides and Heavy Metals in Freshwaters. Journal of Sensors 2020, 2020, https://doi.org/10.1155/2020/8503491.

28. Noori, J.S.; Mortensen, J.; Geto, A. Recent Development on the Electrochemical Detection of Selected Pesticides: A Focused Review. Sensors 2020, 20, https://doi.org/10.3390/s20082221.

29. Das, I.; Goel, N.; Agrawal, N.R.; Gupta, S.K. Growth Patterns of Dendrimers and Electric Potential Oscillations during Electropolymerization of Pyrrole using Mono- and Mixed Surfactants. The Journal of Physical Chemistry B 2010, 114, 12888-12896, https://doi.org/10.1021/jp105183q.

30. Das, I.; Goel, N.; Gupta, S.K.; Agrawal, N.R. Electropolymerization of pyrrole: Dendrimers, nano-sized patterns and oscillations in potential in presence of aromatic and aliphatic surfactants. Journal of Electroanalytical Chemistry 2012, 670, 1-10, https://doi.org/10.1016/j.jelechem.2012.01.023.

31. Afanga, H.; Zazou, H.; Titchou, F.E.; Rakhila, Y.; Akbour, R.A.; Elmchaouri, A.; Ghanbaja, J.; Hamdani, M. Integrated electrochemical processes for textile industry wastewater treatment: system performances and sludge settling characteristics. Sustainable Environment Research 2020, 30, https://doi.org/10.1186/s42834019-0043-2.

32. Vinothkumar, V.; Sangili, A.; Chen, S.-M. Voltammetric Determination of Sudan I by Using $\mathrm{Bi}_{2} \mathrm{WO}_{6}$ Nanosheets Modified Glassy Carbon Electrode. Int. J. Electrochem. Sci. 2020, 15, 2414-2429, https://doi.org/10.20964/2020.03.08.

33. Tkach, V.; Kushnir, M.; Ivanushko, Y.; de Oliveira, S.; Reis, L.; Yagodynets', P.; Kormosh, Z.The Theoretical Description for the Electrochemical Synthesis of Squaraine Dye Doped Conducting Polymer. Appl. J. Env. Eng. Sci. 2020, 6, 51-56.

34. Tkach, V.V.; Storoshchuk, N.M.; Romaniv, L.V.; De Oliveira, S.C.; Luganska, O.V.; Gala, H.B.; Tchikuala, E.F.; Yagodynets, P.I. The theoretical evaluation of the poly(3,4-dimetylpyrrole) cathodic electrodeposition assisted by manganate ions. Vietnam Journal of Chemistry 2018, 56, 440-444, https://doi.org/10.1002/vjch.201800027.

35. Tkach, V.; Kushnir, M.; Storoshchuk, N.; Ivanushko, Y.; de Oliveira, S.; Yagodynets'́, P.; Kormosh, Z. The Theoretical Description for the Confection of the Novel Thiourea-Based Active Surface for Cathodic Conducting Polymer Deposition. Appl. J. Env. Eng. Sci.2020, 6, 143-148. 